\title{
Preparing for Climate Change: Insurance and Small Business
}

\section{Kim Clemo}

AXA Insurance, 1 Aldgate, London EC3N 1RE, U.K.

E-mail: kim.clemo@axa-insurance.co.uk

This paper considers the threat of climate change in the U.K., especially flooding, with regard to the impact that it will have on small and medium-sized enterprises and on the insurance industry itself and the role it plays. It examines the current situation facing the U.K. and then examines the responses being made to this and what can be done in the future to help resolve this issue.

The Geneva Papers (2008) 33, 110-116. doi:10.1057/palgrave.gpp.2510160

Keywords: climate change; flood risk; insurance industry; small businesses

\section{Introduction}

The issue of flooding is a major consideration for the U.K. As the climate in the U.K. changes as a result of global warming, an increase in heavy rainfall, in terms of both frequency and severity, is going to be seen. As a result of this, occurrences of flooding, such as this year's (June and July 2007), are also going to increase in frequency and severity. Melting ice sheets and the thermal expansion of the oceans are also causing sea levels to rise, and this is increasing the threat of coastal flooding due to storm surges.

The insurance industry is likely to feel the brunt of this, as increasing instances of severe flooding will cost the insurance industry a substantial amount of money in claims payouts. For example, the June and July floods of this year alone are estimated to have cost insurers somewhere in the region of $£ 3$ billion pounds in insured losses. ${ }^{1}$

This article will look at the current dangerous situation that the U.K. is facing regarding this issue. In particular, the threat to small and medium enterprises (SMEs) in the U.K. will be considered as well as how the insurance industry is involved there and the ways in which it can help these businesses. SMEs are a very important part of the British economy and arguably its backbone. They play a crucial role in terms of social inclusion, local employment and innovation. SMEs together actually account for over 58.7 per cent of U.K. employment and 51.1 per cent of total business turnover. ${ }^{2}$ AXA Insurance itself is the second largest insurer of SMEs in the U.K., and as such they are a very relevant area to consider when contemplating AXA's response to climate change issues in the U.K.

\footnotetext{
${ }^{1}$ Association of British Insurers (2007).

${ }^{2}$ Crichton (2006).
} 


\section{The current situation}

The U.K. is currently very vulnerable to the impacts of flooding and will become increasingly so if no further action is taken on defences. Today, there are more than 2 million homes at risk from coastal or inland flooding (comprising 10 per cent of total homes in the U.K.), with 400,000 of these classed as being "at very high risk" (greater than 1.3 per cent annual probability of flooding).

The number of people living in coastal communities is projected to rise in the first half of this century, particularly for those over 75 years of age, and this will increase the human and financial cost of any flood events that occur. Strong demand for new land development is likely to have property developers viewing flood plains as places to expand to. The Thames Gateway is a good example of this current situation of using an area of brownfield land stretching 40 miles $(60 \mathrm{~km})$ eastwards from East London on both sides of the River Thames and the Thames Estuary for significant urban regeneration. If nothing is done to address this issue of developing areas at significant risk from flooding, the number of properties at risk of flooding is predicted to increase to 3.5 million by 2080 as a result of these trends and the increasing risk of flooding due to climate change.

Modern construction methods are also exacerbating the situation with an increasing use of fast-track, off-site construction methods and the use of new materials. These are largely untested and there are limited long-term data on how resilient these methods and materials would be to flooding. Couple this with the fact that these techniques are often being used in flood zones and it is possible to see the severe danger that they could pose.

\section{Emerging risk to small businesses}

Small businesses are increasingly at risk from flooding due to the current situation of property development and the increasing risk of flood events actually occurring. The small-scale nature of these businesses often means that they are ill-equipped to deal with their business premises being flooded, and this is especially the case for businesses such as hotels, bars and restaurants, which have no way of continuing their business in the event of a flood.

However, despite this severe danger, research in August 2006 had shown that 90 per cent of SMEs were under-insured, with 70 per cent of businesses in high-risk areas not being concerned that flooding would affect them. ${ }^{3}$ Also in 2006, while 85 per cent of businesses were aware that climate change is an increasing problem for the world, 46 per cent of SMEs thought that climate change was blown out of proportion and only 26 per cent thought that it is a real threat to them. ${ }^{4}$

Surprisingly, when this research was repeated by AXA Insurance in August 2007, it was found that small business leaders are today less concerned that climate

\footnotetext{
${ }^{3}$ Crichton (2006).

${ }^{4}$ Ibid.
} 
change is a serious problem for the world, with the proportion saying they are concerned falling from 85 per cent to 77 per cent. In 2007, 45 per cent of all respondents said that the issue of climate change has been blown out of proportion (compared to 46 per cent in 2006) and 30 per cent said that they see climate change as a real and serious threat to their business (up only marginally from 26 per cent in 2006).

When small businesses were asked how they have prepared against the effects of flooding and severe weather events (and this research was done after the June and July 2007 floods), only 59 per cent said that they are insured against business interruption or loss of earnings. Even among those who have already been affected, insurance takeup is low, with less than two-thirds (62 per cent) of these companies saying they have insurance against weather interruptions. Only 35 per cent of all small business leaders say that they are concerned about the risk of flooding and 65 per cent of businesses do not have a practical contingency plan in case they are affected by severe weather. Similarly, only 27 per cent have reviewed their commercial insurance to tackle the threat from severe weather conditions, only 24 per cent have reviewed their weather proofing and 20 per cent or fewer of all small companies have introduced home working or flexible working or sought advice from government on how to react to severe weather disruptions.

SMEs are therefore at great risk of being put out of business entirely by a major flooding incident due to being inadequately prepared for the event. When considering substantially under-insured properties, insurers are not obliged to pay out the full amount covered by the policy if it can be shown that the property is indeed underinsured. SMEs being put out of business in this way could cause a rise in the cost to the economy of up to 30 or 40 times what it is now by 2080 if current climate change and attitudes to development and adaptation to it continue. This would cost the U.K. economy up to $£ 42$ billion every year in today's prices as a result of business interruption. ${ }^{5}$

Finally, a lot more businesses are likely to be at risk in the future due to a trend of business downsizing currently occurring in Britain, which affects how severely a business will be impacted by a flood. The outsourcing of storage and distribution operations to third parties also has the potential to reduce business resilience as the business would then lose direct control over these operations and would find it hard to deal with these being put out of action by a flood.

\section{Role of the insurance industry}

The U.K. insurance industry has a vested interest in these issues. In every nonexceptional year, insurance companies pay out between $£ 500$ million and $£ 1$ billion in weather-related claims. These figures are obviously increasing because of particularly severe events such as the floods of 2007 and payouts are likely to rise as the effects of climate change become more widely felt.

\footnotetext{
${ }^{5}$ Ibid.
} 
The insurance industry helps ease the burden on customers affected by weather events such as floods by:

- Managing the repair process.

- Bringing in supplies and quality assured repairers, even if local suppliers are overwhelmed.

- Providing for temporary accommodation while repairs are undertaken.

- Business Continuity Planning: If taken out as part of the cover, the insurance company in question will provide alternative premises for small business to run out of while repairs are in progress and appropriate resources to go with that as needed.

The current state of affairs basically has U.K. insurers subsidising flood insurance as a result of the Association of British Insurer's Statement of Principles on the Provision of Flood Insurance, ${ }^{6}$ a form of continuation of the terminated Insurance Guarantee (1961). The average premium of a domestic property in a high-risk flood zone is $£ 233$. If you assume a medium probability of a loss within the 1-in-75-year range (the definition of a high-risk property) and the fact that the average domestic flood claim cost is $£ 15,000$, then by all rights the flood risk premium alone should be approximately $£ 600$ per year. As can be seen, with increasing occurrences of severe flooding, this policy will soon be unsustainable if something is not done to tackle this issue. If you couple this with the apparent lack of awareness about flood risk by SMEs, then you can see that this area is of particular concern to the insurance industry.

\section{The response}

As seen so far, the current situation regarding small businesses and the insurance industry is not an acceptable state to be in. As such, a response to try and solve these issues must be made.

\section{What has already been done?}

The insurance industry, with AXA Insurance as the example here, has a wealth of risk management expertise and is willing to contribute to the debate and the actions required to respond to climate change and its impacts. As part of the initiative to be part of the solution, AXA Insurance commissioned Professor David Crichton to produce a report on the impact of climate change on small and medium-sized enterprises, ${ }^{7}$ which was published in August 2006. It is this report that turned up many of the issues that have been discussed in this article and from which many of the figures and statistics have been drawn. The survey on which this report was based was repeated in August 2007.

Following this 2006 report, AXA also produced a guide ${ }^{8}$ that was designed to inform small businesses on how best to prepare themselves for climate change and

\footnotetext{
${ }^{6}$ Association of British Insurers (2003).

${ }^{7}$ Crichton (2006).

${ }^{8}$ AXA Insurance (2006).
} 
make sure that their business is resilient enough to survive a major flooding event. These guidelines include such things as ensuring that businesses are resilient by avoiding the use of basements, installing flood protection systems, etc. It also strongly encourages the proper utilisation of Business Continuity Planning, as a means to be prepared, and cooperation with other businesses to exchange ideas and organise mutual flood warning systems.

The Association of British Insurers (ABI) is also very proactive in the climate change debate in the U.K. and has already taken many actions regarding this issue. It has commissioned surveys of coastal flooding risk since the early 1990s, including the examination of particular areas that are at risk of flooding and investigations into the condition of coastal flood defences. It also commissioned Entec to carry out a research project to inform about their future policy on flood risks. ${ }^{9}$ They have also carried out research into the risk of flooding in the proposed Thames Gateway developments. ${ }^{10} \mathrm{In}$ addition to this, it is working to raise awareness of climate change issues and threats among relevant groups.

One crucial consideration on this topic is the ongoing interaction between the ABI and the U.K. Government. The ABI is involved in lobbying the government ${ }^{11}$ to focus flood defence spending on areas with the greatest need and to increase spending on flood defences in real terms to protect more areas more quickly. It is also working to get the government to improve its planning protocols regarding the issues discussed in "The Current Situation" section of this article. It is also working hard to help the government understand the role that the insurance business faces in dealing with these issues, and what stands to be lost if they are not addressed.

\section{Challenges for the future}

As can be seen, much work is already being done regarding the issues of climate change and its impact on the insurance industry and small businesses. However, much more needs to be done and insurers must continue to lobby the government on the risk of new developments in flood zones and the necessity of stricter laws regarding this issue. It has also been suggested that insurers themselves take the lead in this area by taking a harder line on buildings constructed in risk areas with materials that are not certain to be resilient to flooding. By refusing to quote for such properties, or by increasing premiums substantially for coverage here, developers will lose out as potential buyers will be put off by their inability to find a quote for potential new properties. If the government refuses to move on this issue, this might eventually become a reality.

There also needs to be a closer partnership between insurers and the government so that the government can make optimum use of the industry's expertise in risk management and its extensive databases of flood data.

\footnotetext{
${ }^{9}$ Association of British Insurers (2000).

10 Association of British Insurers (2005).

${ }^{11}$ Association of British Insurers, "Flooding and Insurance”, http://www.abi.org.uk/Display/Display_ Popup/default.asp?Menu_ID=1090\&Menu_All=1,1088,1090\&Child_ID = 553 .
} 
As investors, insurers should influence companies over their carbon emissions and environmental policies. There is a lot of potential here for the insurance industry to promote sound environmental practice by helping to cut the carbon footprints of the companies they are investing in as well as their own carbon footprints. In relation to this, the insurance industry should also support and strengthen the European Emissions Trading Scheme ${ }^{12}$ as one of the means for meeting the U.K.'s 2010 objectives for greenhouse gas emission reductions.

Sustainable flood management solutions should also be encouraged to ensure the future ecological quality of our rivers and lakes and to provide more cost-effective and natural flood protection. Incentives can also be offered to promote more sustainable and responsible behaviour in developments. This can be linked in to an overall building standards policy that would encourage more resilient building standards by setting guidelines for what the insurance business will cover with regard to properties in risk areas. Insurance companies could then refuse cover for buildings that did not meet these standards. The best solution, however, would be for these standards to be implemented as government policy on a national level.

There are also five key challenges for the insurance industry in the future. It will have to adapt in the following ways:

1. Exposure management: accurately assessing exposures to major catastrophic events, in order to maintain a smooth and resilient risk transfer mechanism which sustains human activities.

2. Communication: raising awareness amongst customers, promoting responsible behaviour for Personal Lines and SME Business Clients.

3. Pricing: incorporating climate change impacts within pricing mechanisms.

4. Product development: developing tailor-made insurance products that assist the development of renewable energies and contribute to mitigating climate change effects.

5. Sustainability: taking into account long-term sustainable development perspectives when assessing investment, in addition to short- and medium-term financial criteria.

\section{Conclusion}

We have seen in this article that the U.K. is very exposed to the risk of severe weather events, and these occurrences will become more common as a result of climate change. This poses a major threat to small and medium-sized enterprises that are particularly vulnerable to business interruption caused by weather events such as flooding. The interruption of sizeable portions of SMEs during major events costs the U.K. economy a significant amount, and the claims costs resulting from this are becoming more and more of an issue to insurance companies that are currently subsidising flood premiums.

\footnotetext{
${ }^{12}$ DEFRA "European Union Emissions Trading Scheme", http://www.defra.gov.uk/environment/ climatechange/trading/eu/index.htm.
} 
116

As a result, the insurance industry is working very closely with the government to develop better flood defences and produce stricter development guidelines when building in high-risk areas. However, more must be done as there is still a lot of ground to cover. Insurance companies should work to promote sustainable practices off their own backs as well as interact with companies they invest in and possibly revise their own flood coverage policy if sufficient action is not taken by the government.

AXA Insurance itself welcomes the opportunity to play a leading role in the climate change debate in the U.K. and will continue to work to help fight climate change and adapt to its effects in this country.

\section{Acknowledgements}

I thank Daniel Hubbard for contributing to this article. Except where stated, all statistics and figures are provided by AXA Insurance U.K.

\section{References}

Association of British Insurers (2000) Inland Flood Risk - Issues Facing the Insurance Industry, General Insurance Research Report, No.10, London: Association of British Insurers.

Association of British Insurers (2003, revised 2005) Statement of Principles on the Provision of Flood Insurance, London: Association of British Insurers.

Association of British Insurers (2005) Making Communities Sustainable. Managing Flood Risks in the Government's Growth Areas, Final Technical Report (February), London: Association of British Insurers,. Association of British Insurers (2007) 'Latest flood costs', taken from http://www.abi.org.uk/.

AXA Insurance (2006) Preparing for Climate Change- a Practical Guide for Small Businesses, London: AXA Insurance.

Crichton, D. (2006) Climate Change and its Effects on Small Businesses in the U.K., London: AXA Insurance.

\section{About the Author}

Kim Clemo joined AXA Insurance in 2004 as Human Resources Director. She is an experienced leader with expertise in organisational change, implementation of major change programmes, strategy development, communication and corporate responsibility. Kim was appointed Climate Change Director in January 2007 with the focus on developing a leadership influencing strategy, developing internal carbon management strategy and awareness programme for employees and developing products in areas that include exposure management, communication and raising awareness with customers, promoting responsible behaviour, pricing through the incorporation of climate change and developing tailor-made insurance products that reward and incentivise customers. Kim has a diverse career history. She spent 10 years working in the licensed retail and brewing industries in several roles including Regional Programme Manager, Human Resources Director and Commercial Services Director. Kim has now been working in the financial services industry for 8 years mainly as Human Resources Director and currently as Climate Change Director. 